\title{
Dilemas bioéticos y jurídicos de la reproducción asistida en la sociedad actual en España
}

\author{
Bioethical and legal dilemmas of assisted \\ reproduction in today's society in Spain
}

\section{Dilemas bioéticos e jurídicos da reprodução \\ assistida na sociedade de hoje na Espanha}

Fecha de recepción: 23 de junio de 2017

Fecha de evaluación: 12 de septiembre de 2017

Fecha de aceptación: 30 de septiembre de 2017

Disponible en línea: 21 de noviembre de 2017

Pablo Enguer Gosálbez

Francisca Ramón Fernández"

\author{
Cómo citar: \\ Enguer Gosálbez, P. y Ramón Fernández, \\ F. (2018). Dilemas bioéticos y jurídicos de la \\ reproducción asistida en la sociedad actual en \\ España. Revista Latinoamericana de Bioética, 18(1), \\ 104-135. \\ Doi: https://doi.org/10.18359/rlbi.3160
}

* Grado en Biotecnología y máster universitario en Economía Agroalimentaria y del Medio Ambiente, Universitat Politècnica de València. Escuela Técnica Superior de Ingeniería Agronómica y del Medio Natural (ETSIAMN). Técnico Medio. Personal en Investigación en la Universitat Politècnica de València, Valencia, España. Correo electrónico: pabengos@etsiamn.upv.es. ORCID: http://orcid.org/0000-0002-4577-5024.

** Licenciada y doctora en Derecho, Universitat de València. España. Profesora titular de Derecho Civil en la Universitat Politècnica de València, adscrita a la Escuela Técnica Superior de Ingeniería del Diseño (ETSID), Valencia, España. Correo electrónico: frarafer@urb.upv.es. ORCID: http://orcid.org/0000-0002-0936-8229. 
Este trabajo analiza algunos problemas jurídicos y bioéticos que no están resueltos por la legislación aplicable a la reproducción asistida, uno de los campos más controvertidos de la medicina y la biotecnología humana. Se centra especialmente en el ámbito de los nuevos modelos familiares heterosexuales y homosexuales, así como el caso de parejas que tengan una enfermedad preexistente, la controversia referente a la selección de embriones no portadores de enfermedades en el caso del diagnóstico genético preimplantatorio, la selección del sexo, la fecundación in vitro mixta, procreación post mortem, entre otros.

En definitiva, se presta atención al modo como se ha efectuado la regulación y a las valoraciones éticas, con el propósito de alcanzar conclusiones después de conocer los argumentos emitidos por la doctrina y reflexionar acerca de los aspectos mejorables de nuestra legislación, con propuestas concretas de lege ferenda.

Palabras clave: reproducción humana, biología humana, legislación, familia, embrión.

\section{Abstract}

This paper analyzes some legal and bioethical problems that are not solved by the legislation applicable to assisted reproduction, one of the most controversial fields of medicine and human biotechnology. It focuses especially on the area of new heterosexual and homosexual family models, as well as the case of couples with a pre-existing disease, the controversy regarding the selection of non-disease carrier embryos in the case of preimplantation genetic diagnosis, sex selection, mixed in vitro fertilization, and post mortem procreation, among others.

In short, attention is paid to the way in which regulation and ethical assessments have been carried out, with the purpose of reaching conclusions after knowing the arguments emitted by the doctrine and reflecting on the improbable aspects of our legislation, with concrete proposals for lege ferenda.

Keywords: Human reproduction, human biology, legislation, family, embryo.

\section{Resumo}

Este trabalho analisa alguns problemas jurídicos e bioéticos que não são resolvidos pela legislação aplicável à reprodução assistida, um dos domínios mais controversos da medicina e a biotecnologia humana. Concentra-se especialmente no campo de novos modelos familiares heterossexuais e homossexuais, bem como no caso de casais com doença pré-existente, a controvérsia referente à seleção de embriões não portadores de enfermidades no caso do diagnóstico genético pré-implantação, a seleção de sexo, a fertilização mista in vitro, procriação post mortem, entre outros.

Em suma, é dada atenção à forma como a regulamentação foi realizada e as avaliações éticas, com o objetivo de chegar às conclusões após conhecer os argumentos emitidos pela doutrina e refletir sobre os aspectos melhoráveis de nossa legislação, com propostas concretas de lege ferenda.

Palavras-chave: reprodução humana, biologia humana, legislação, família, embrião. 


\section{Introducción}

Los avances científicos alcanzados en el campo de la medicina durante el siglo XX y comienzos del siglo XXI han sido muy relevantes. En ese periodo de la historia, se ha conseguido un nivel de innovación superior al que se haya podido conseguir en cualquier otra época. Los hitos alcanzados en medicina reproductiva son un ejemplo que constata este hecho.

Las técnicas de reproducción humana asistida se han popularizado en las sociedades occidentales y una gran cantidad de personas ha podido tener acceso a ellas. Todo esto ha hecho necesaria la regulación de dichas técnicas.

En el caso de España, estos nuevos métodos de reproducción han obtenido una muy amplia difusión, siendo uno de los países europeos en los que mayor número de tratamientos se realizan. Así lo corroboran los datos proporcionados por el Registro de la Sociedad Española de Fertilidad: Técnicas de reproducción asistida (IA y FIV/ICSI) (2012), único registro del país que recoge el número de ciclos de técnicas de reproducción asistida (TRA) llevados a cabo. Según este documento, en 2012 se hicieron en España 70.961 ciclos de alta complejidad (fecundación in vitro, donación de ovocitos, criotransferencias, diagnóstico genético preimplantacional, congelación de ovocitos, maduración in vitro) y 28.596 ciclos de baja complejidad (inseminación artificial con semen de cónyuge o de un donante anónimo).

En lo referente a la legislación, en nuestro país ya se han desarrollado dos leyes sobre reproducción asistida, incluyendo una modificación de la primera:

- Ley 35/1988, del 22 de noviembre, sobre técnicas de reproducción asistida modificada por la Ley 45/2003, del 21 de noviembre.
- Ley 14/2006, del 26 de mayo, sobre técnicas de reproducción humana asistida

Todo ello exige un compromiso por parte de los científicos y demás profesionales del sector por estar al día en todo momento y poder analizar la legalidad de los supuestos que se les presentan, así como asesorar de la mejor manera posible a los pacientes.

La decisión de optar por las técnicas de reproducción asistida puede venir motivada por distintas razones de tipo médico y social. La normativa reguladora de dichas técnicas ha ido evolucionando en consonancia con los cambios de la sociedad actual, pero no por ello ha ido solventando diversos problemas éticos y jurídicos. Con este artículo se pretende abordar aspectos tan polémicos como el acceso a las TRA por distintos modelos de familia, el diagnóstico genético preimplantatorio o la elección del sexo y la selección de embriones no portadores de enfermedades, entre otros.

Dichos aspectos son tratados por medio de la legislación acerca de estos y ofreciendo puntos de vista de distintos autores, para así posicionarnos y aportar argumentos a favor de nuestra teoría. No se parte de un posicionamiento previo, sino que se buscan argumentos razonados a partir de los cuales cada persona pueda emitir un juicio de valor, reflexionar sobre la regulación de las TRA y aportar opiniones y sugerencias que contribuyan a mejorar nuestro ordenamiento jurídico en materia de reproducción asistida.

Se trata, en definitiva, de una reflexión sobre la regulación actual, así como de una aportación de algunas sugerencias, propuestas concretas de lege ferenda que contribuyan a mejorar nuestro ordenamiento jurídico en materia de reproducción asistida. 
Esterilidad e infertilidad: causas, diagnóstico y razones de la regulación de las Técnicas de Reproducción Asistida

Según Federico Pérez Milán, en su texto "Bioética y ley en reproducción humana asistida. Manual de casos clínicos" (Abellán y Sánchez-Caro, 2009), se entiende por esterilidad la incapacidad para conseguir gestación tras un año de relaciones sexuales con normal frecuencia y sin la utilización de métodos anticonceptivos. Esta definición se apoya en el dato aportado por la Sociedad Española de Fertilidad (SEF) (2012): el 85\% de las parejas en edad reproductiva logra una gestación durante el primer año de intentos. Por tanto, una de cada seis parejas está afectada por la esterilidad.

Los posibles factores causales de esterilidad humana se pueden incluir en alguno de los siguientes grupos:

- Alteraciones en la producción de gametos, tanto masculinos como femeninos.

- Alteraciones que dificultan la interacción entre los gametos.

- Alteraciones de la implantación embrionaria.

Al profundizar en este aspecto, se descubre que los factores causales de la esterilidad más frecuentes son el factor masculino, el tubárico y peritoneal y el ovárico. Además, hasta en un $20 \%$ de los casos, la esterilidad tiene un origen desconocido. Por otra parte, el término "infertilidad" hace referencia a la incapacidad para desarrollar gestaciones que evolucionen hasta la viabilidad fetal.

La infertilidad puede estar provocada por alguno de estos factores causales:
- Alteraciones genéticas (constituyen la causa más frecuente).

- Alteraciones anatómicas del útero.

- Alteraciones endocrinas y metabólicas.

- Infecciones.

- Trastornos inmunes y vasculares.

Respeto a cómo se diagnostica la esterilidad, podemos indicar que este proceso consiste en la detección de la causa que provoca la esterilidad para, posteriormente y siempre que sea posible, pasar a la corrección del trastorno eligiendo el tratamiento más oportuno. Existen múltiples tipos de pruebas de diagnóstico. Actualmente, se escoge la prueba ideal considerando especialmente la fiabilidad y la utilidad clínica de esta, aunque también se tienen en cuenta factores como el coste, la complejidad y las características particulares de cada paciente.

El primer paso es la entrevista con ambos miembros de la pareja para averiguar sus antecedentes reproductivos y sus síntomas. Seguidamente, la mujer es sometida a una exploración y, si se cree conveniente, al varón se le realizará una exploración por parte de un andrólogo. Existen tres grupos de pruebas que se aplican en todos los casos:

- Análisis de la calidad seminal mediante seminograma para evaluar la cantidad, movilidad y morfología de los espermatozoides.

- Pruebas de normalidad anatómica y funcional del útero y las trompas de Falopio. Se realizan mediante pruebas de imagen, como la ecografía transvaginal o un tipo de radiografía denominada histerosalpingografía. 
- Pruebas para determinar la calidad de la ovulación: estudio de la historia menstrual, curvas de temperatura basal (de poca utilidad), ecografía, resonancia magnética nuclear y determinaciones hormonales (especialmente de progesterona).

En algunos casos, puede ser aconsejable completar el diagnóstico con pruebas seminales avanzadas, una biopsia testicular, una laparoscopia, una histeroscopia u otro tipo de estudios.

Entonces, nos podemos preguntar por qué resulta necesaria la regulación de las técnicas de reproducción asistida

Con la aparición de las TRA, las parejas afectadas por la esterilidad e infertilidad pueden acceder hoy en día a la posibilidad de tener hijos. Además, no solo las parejas heterosexuales demandan estos servicios, sino que parejas homosexuales y mujeres solas también desean acceder a ellos. Por otra parte, existen otras personas afectadas por enfermedades genéticas transmisibles a la descendencia que reclaman la utilización de estas técnicas para evitar que sus hijos hereden estas patologías.

De este modo, durante los últimos años, la demanda de servicios de reproducción asistida ha sufrido un progresivo incremento, lo cual se debe, por un lado, a la creciente accesibilidad a las técnicas reproductivas; por otro lado, la transformación del papel que juegan las mujeres en la sociedad también ha contribuido a ello, ya que su incorporación masiva al mercado laboral conlleva el retraso de su "edad reproductiva social". Cabe señalar que el periodo de máxima fecundidad de la mujer es el que comprende entre los 20 y los 30 años de edad. Así pues, la voluntad de tener descendencia a una edad avanzada se ha postulado como la principal causa del auge de las TRA.

Como consecuencia, 3 de cada 100 niños nacidos en España lo hacen gracias a la ayuda de las TRA, siendo el tercer país europeo donde más ciclos se realizan, después de Francia y Alemania (SEF, 2011).

Todos estos aspectos que han revolucionado el panorama sanitario y social en las últimas décadas han hecho necesaria la regulación legislativa de las TRA.

A continuación, se presenta la evolución histórica acerca de la actual Ley 14/2006, de 26 de mayo, sobre las TRA.

Las TRA empezaron a desarrollarse en España en los años 70, puesto que antes la solución a los problemas de esterilidad era la inseminación artificial (IA). Es ya en 1984 cuando nace la primera niña mediante fecundación in vitro (FIV) en España, y solo cuatro años más tarde se publica la Ley $35 / 1988$, primer texto legislativo sobre las TRA en nuestro país.

El principal motivo que condujo a la reforma de la Ley 35/1988 fue la acumulación de embriones congelados que se estaba originando en los centros de reproducción españoles, que sobrepasaban el límite de cinco años que estipulaba el artículo 11.3. Los avances científicos que aparecieron a partir de 1988 también fueron otra de las razones para llevar a cabo una actualización de la norma.

Ya en 1998, la Comisión Nacional de Reproducción Humana Asistida (CNRHA) publicó su primer informe, en el que proponía ampliar los plazos de congelación de semen y embriones, y permitir la congelación de ovocitos con fines reproductivos. En 2003, la CNRHA y el Comité Asesor de Ética 
en Investigación Científica y Tecnológica (CAEICT) propusieron la modificación de la Ley 35/1988 para que se permitiera la investigación con embriones humanos congelados que hubieran rebasado el plazo legal (cinco años), en lugar de destruirlos directamente. Como respuesta a esta situación, la Ley 45/2003 autorizaba la investigación con embriones congelados bajo condiciones muy restrictivas, y solo con los generados antes de la entrada en vigor de la ley; por esta razón, cuando estos se hubieran agotado, no se habría podido continuar investigando con embriones humanos.

Entre los pocos cambios que introdujo la Ley 45/2003 también estaba la prohibición de generar más de tres embriones por ciclo reproductivo (los tres son transferidos en un solo ciclo), salvo en casos excepcionales. Esta medida provocó algunos inconvenientes:

1. El rendimiento de las TRA se redujo, ya que no es lo mismo transferir los tres embriones de mayor calidad, elegidos de entre un grupo de seis y ocho embriones, que transferir los tres únicos embriones que se hayan generado (Molina, Duque y Alfonso, 2006).

2. En aquellos casos en los que el primer intento de embarazo no había tenido éxito, las parejas tuvieron que enfrentarse a los problemas físicos, psicológicos y económicos que conlleva reiniciar el proceso reproductivo completo (Terribas, 2006a).

3. Incluso cuando el proceso reproductivo había tenido éxito, la pareja o la mujer sola pueden tener el deseo de concebir otro hijo, por lo cual disponer de embriones criopreservados es muy útil en este caso (Pérez Milán, 2003).
Otro aspecto conflictivo de la Ley 45/2003 fue la obligación de destinar los embriones sobrantes (generados en casos excepcionales) exclusivamente para la reproducción de la pareja progenitora o para la donación con fines reproductivos, ya que se contradice con la prohibición de la Ley 35/1988 de transferir al útero embriones anormales. En otras palabras, muchos embriones no debían ser donados por el hecho de haber sido "generados a partir de ovocitos de mujeres mayores de 35 años o de espermatozoides de hombres mayores de 50 , o por pertenecer a parejas con antecedentes de enfermedades infecciosas, alteraciones genéticas o cuyo fenotipo exótico dificulta la existencia de parejas receptoras compatibles" (Molina et al., 2006, p. 64).

La CNRHA mantuvo una postura muy crítica con la Ley 45/2003 y solicitó su reforma. Así pues, solo estuvo en vigor durante poco más de dos años, hasta la aparición de la Ley 14/2006.

En relación con las creencias religiosas, la Iglesia católica otorga al embrión el mismo respeto que a las personas nacidas y considera que el acto conyugal debe ser el único medio para la procreación, y así queda estipulado por la Congregación para la Doctrina de la Fe, tanto en la Instrucción Donum vitae (1987) como en la Instrucción Dignitas personae (2008). Por tanto, solo se aceptan las técnicas que ayudan a la fecundidad del acto conyugal y se rechazan la IA, la FIV (esta se denuncia especialmente por la elevada cantidad de embriones generados que no llegan a nacer), la inyección intracitoplasmática de espermatozoide (ICSI), el diagnóstico genético preimplantacional (DGP) y la criopreservación de embriones (debido a los riesgos de la congelación y descongelación y a que la mayoría de embriones quedan "huérfanos") 
(apartado 18, Dignitas personae) y son usados en investigación como simple "material biológico", lo que conlleva su destrucción (apartado 19, Dignitas personae). Además, también se opone a la donación de embriones.

En el protestantismo, se aceptan las TRA mientras que no haya pérdida de embriones y los gametos provengan de los miembros de la pareja (declaraciones de los cristianos evangélicos de las Jornadas sobre Bioética, 1989 y 2000).

El islam defiende que, hasta 120 días tras la fecundación, los embriones pertenecen a los progenitores, que pueden autorizar una intervención sobre estos (Martín, 2005), pero se opone a la donación de embriones a otras parejas porque se cree imprescindible conocer la identidad del padre. También rechaza la donación el judaísmo, por el riesgo de incesto, así como la cesión de embriones para investigación, porque supone su destrucción (García, 2004).

Vamos a tratar, a continuación, distintos problemas que se plantean en torno a la reproducción asistida y que no están resueltos por la legislación o que plantean algunas dudas legislativas.

\section{Análisis de la actual Ley 14/2006 sobre Técnicas de Reproducción Asistida. Principales dilemas que se plantean}

\section{Los nuevos modelos familiares que tienen acceso a las Técnicas de Reproducción Asistida}

El concepto de familia ha experimentado una progresiva evolución, de modo que hoy en día la libertad del individuo prevalece so- bre la estructura familiar. El modelo tradicional de familia ha consistido en el matrimonio canónico, heterosexual, naturalmente indisoluble y enfocado a la procreación. Posteriormente, la reforma protestante promovió el matrimonio civil y el Código Civil francés de 1804 fue la primera normativa que permitía el divorcio (Morales Moreno y Miquel González, 2007). A este modelo clásico se le han ido sumando otros, como las uniones no matrimoniales (uniones de hecho, reconocidas legalmente), las familias monoparentales o el matrimonio homosexual, que paulatinamente se han ido contemplando jurídicamente en España. No obstante, la Constitución Española de 1978 no menciona otras formas de convivencia en pareja aparte del matrimonio (artículo 32). Además, reconoce el derecho a la protección de la familia (artículo 39), pero no define el término "familia". El Tribunal Constitucional, en la Sentencia 222/1992, de 11 de diciembre de 1992, afirmó que existen diversos tipos de enlaces que se incluyen en la concepción constitucional de familia y merecen el amparo que la Constitución establece para estos.

Más tarde, la Ley 13/2005, del primero de julio, por la que se modifica el Código Civil en materia de derecho a contraer matrimonio, legalizó el matrimonio homosexual en España. En su disposición adicional primera se ordena que todas las referencias al matrimonio presentes en nuestro ordenamiento jurídico deben entenderse aplicables tanto a matrimonios heterosexuales, como homosexuales.

Así pues, la evolución de la sociedad española ha desembocado en la Ley 14/2006, más permisiva en este sentido que las de los países de nuestro entorno, en la cual se dictamina que tanto los matrimonios (heterosexuales $\mathrm{u}$ homosexuales femeninos) como las pare- 
jas de hecho heterosexuales y la mujer sola tienen derecho al acceso a las TRA.

En ocasiones, los matrimonios homosexuales femeninos desean llevar a cabo una fecundación in vitro, de modo que a una de ellas se le extraiga el ovocito, se fecunde y se transfiera al útero de la otra mujer. Llevar a cabo este método se podría interpretar como un incumplimiento del artículo 1.1 de la Ley 14/2006, en el que se establece que las TRA deben estar clínicamente indicadas, ya que un mismo miembro de este matrimonio podría aportar el ovocito y desarrollar la gestación (Abellán y Sánchez-Caro, 2009).

Una mujer separada puede someterse a una TRA sin que exista una sentencia de separación o divorcio, ya que bastaría con un documento que probase la separación de hecho (Abellán y Sánchez-Caro, 2009).

Resulta evidente que una mujer casada no puede someterse a una TRA con otra persona (excluyendo donantes anónimos) que no sea su marido, a no ser que este dé su consentimiento (artículo 6.3, Ley 14/2006). Pero ¿podría un hombre casado someterse a una TRA con una mujer que no sea su esposa, sin el consentimiento de esta? Existen razones para negarle el acceso a la TRA a este hombre (Abellán y Sánchez-Caro, 2009):

1.1) Si no se le niega, estaríamos ante un caso de discriminación entre hombres y mujeres, lo cual es anticonstitucional.

2. La Ley $14 / 2006$ establece que aquellas parejas que pueden acceder a las TRA son los matrimonios y las parejas de hecho. Este caso sería otra variante de pareja no contemplada.
3. No es éticamente aceptable que un centro de reproducción asistida se preste a colaborar en el engaño de un hombre a su esposa.

En cuanto a las parejas de hecho, en el artículo 8.2 de la Ley 14/2006 se habla del consentimiento del "varón no casado", por lo que no puede entenderse que se deba aplicar también para la "mujer no casada" (la que sería miembro de una pareja de hecho de lesbianas), ya que la disposición adicional primera de la Ley 13/2005 alude únicamente a enlaces matrimoniales y no a parejas de hecho. Es por ello que las parejas de hecho homosexuales femeninas no pueden acceder a las TRA como tal, sino que tendrían que acceder como mujeres solas.

En el caso de una pareja de hecho constituida por un transexual (mujer sometida a una intervención quirúrgica para transformarse en hombre) y su compañera, ¿podrían acceder a las TRA como pareja de hecho? La respuesta es afirmativa, siempre y cuando la persona transexual haya regularizado su condición de varón en el Registro Civil, y así esta asumiría la paternidad del futuro hijo. Cabe señalar que el artículo 5 de la Ley 3/2007, del 15 de marzo, reguladora de la rectificación registral de la mención relativa al sexo de las personas, afirma que la rectificación del sexo "permitirá a la persona ejercer todos los derechos inherentes a su nueva condición".

Actualmente, distintas comunidades autónomas han legislado para garantizar el acceso a los bancos de óvulos o semen y a las TRA incluyendo como beneficiarias a todas las personas con capacidad gestante o sus parejas.

Respecto a la determinación de la filiación de las personas nacidas mediante las TRA, el artículo 6.3 de la Ley 14/2006 dice, literalmente, que cuando una mujer casada desea 
someterse a una TRA "se precisará el consentimiento de su marido, a menos que estuvieran separados legalmente o de hecho y así conste de manera fehaciente".

A pesar de que el mencionado artículo hable de "marido", en el caso de los matrimonios formados por dos mujeres, la que se someta a la TRA también va a necesitar el consentimiento de la otra mujer (disposición adicional primera, Ley 13/2005), lo cual significa que la filiación del futuro hijo será matrimonial, es decir, será hijo de dos madres. Ahora bien, en cuanto a la determinación de la filiación de los nacidos mediante TRA, existe un aspecto discriminatorio contra el matrimonio homosexual. Mientras que un marido (de un matrimonio heterosexual) puede obtener la paternidad mediante su propia firma del consentimiento mencionado en el artículo 6.3 de la Ley $14 / 2006$, la mujer (de un matrimonio homosexual) que no ha dado a luz, para que le sea reconocida la maternidad, debe realizar una manifestación expresa previa al nacimiento ante el encargado del registro civil del domicilio conyugal (Farnós Amorós, 2011).

En el caso de las parejas de hecho, y aunque se hayan inscrito en el registro municipal o autonómico, el consentimiento del varón para que su compañera sentimental se someta a una TRA no es obligatorio, sino optativo. Pero en el caso de que otorgue su consentimiento, este acto se tendrá en cuenta como una asunción de la paternidad del hijo venidero, incluso cuando los gametos masculinos provengan de un donante. Así queda establecido en el artículo 8.2 de la Ley 14/2006:

Se considera escrito indubitado a los efectos previstos en el artículo 49 de la Ley del Registro Civil el documento extendido ante el centro o servicio autorizado en el que se refleje el consentimiento a la fecundación con contribución de donante prestado por varón no casado con anterioridad a la utilización de las técnicas. Queda a salvo la reclamación judicial de paternidad.

En el caso de una pareja de hecho formada por dos mujeres, aquella que no ha dado a luz, si desea también ser madre legal del niño/a, debería iniciar un expediente judicial de adopción.

\section{Distintos supuestos legales en los que se plantea si se debe acceder o no a una Técnica de Reproducción Asistida: discapacidad e incapacidad y el caso de enfermedades previas}

En determinados casos, la mujer que quiere someterse a un TRA no se encuentra en las condiciones psicofísicas más adecuadas para ello (en muchos casos por tener una edad avanzada), y el médico debe informarle de ello con anterioridad al inicio del tratamiento, como dispone el artículo 6.2 de la Ley 14/2006.

Por otra parte, en el artículo 2.1 b) de la ya derogada Ley 35/1988 se citaba como condición obligatoria para llevar a cabo un TRA que la mujer usuaria presentara un buen estado de salud psicofísica, lo cual ya no figura en la actual ley de reproducción; ahora se permite el acceso a estas técnicas a un mayor número de personas.

Esta evolución en la normativa viene reforzada por la disposición adicional quinta de la Ley 14/2006 en la que se asignan a las personas con discapacidad los derechos y las facultades reconocidos en dicha Ley, sin representar su condición de discapacidad un motivo para la discriminación, con arreglo a lo dispuesto en la ya derogada Ley 51/2003, del 2 de diciembre, de igualdad de oportu- 
nidades, no discriminación y accesibilidad universal de las personas con discapacidad. La norma que sustituye a esta ley es el Real Decreto Legislativo 1/2013, del 29 de noviembre, por el que se aprueba el texto refundido de la Ley General de derechos de las personas con discapacidad y de su inclusión social.

En la misma disposición de la Ley 14/2006 se establece que "la información y el asesoramiento a que se refiere esta ley se prestarán a las personas con discapacidad en condiciones y formatos accesibles apropiados a sus necesidades".

La mujer sola o miembros del matrimonio que deseen someterse a una TRA deben ser capaces de prestar un consentimiento "libre, consciente y formal" (artículo 6.1 y 6.3, Ley 14/2006), por lo que ninguna persona puede dar este consentimiento en nombre de otra. En España, se le presupone capacidad a una persona mientras no se demuestre lo contrario (artículo 199 del Código Civil). Si una persona no está incapacitada legalmente, debe ser el equipo médico el que valore su estado psíquico y su capacidad para tomar decisiones.

Serna Moreño (2007) distingue tres tipos de incapacidades, según su idoneidad para el acceso a las TRA:

1. Sensoriales (problemas de audición o visión). No deben ser un inconveniente para el acceso a las TRA.

2. Físicas. Los profesionales pueden negarse a realizar la TRA en caso de anomalía grave.

3. Psíquicas. El acceso a la TRA depende de que la mujer comprenda la información relativa al tratamiento.
Esta postura no analiza el impacto de las incapacidades de los progenitores en la descendencia que podrían llegar a tener, sino solamente en la madre, por lo que es criticable en ese aspecto.

A partir de este tipo de situaciones pueden derivarse discrepancias entre las intenciones de los interesados en someterse a la técnica y la opinión médica. Desde una perspectiva bioética, este conflicto puede resolverse analizando dos de los principios éticos que rigen la práctica médica: el principio de autonomía mediante el cual cualquier paciente capaz, maduro, informado y que asume los riesgos de un tratamiento puede decidir por sí mismo si se somete a este o no; y el principio de no maleficiencia, según el cual el embarazo puede agravar los problemas de salud que tenga la mujer e incluso comprometer la salud de su descendencia, por lo que se le puede privar de las TRA; siguiendo el principio del juramento hipocrático primum non nocere, no se debe causar un daño a sabiendas (Beauchamp y Childress, 1979).

Hay autores que sitúan el principio de no maleficiencia en un nivel jerárquico superior al de autonomía (Gracia, 1991), siendo esta corriente la que aplica la legislación española. Según el artículo 3.1 de la Ley 14/2006, las TRA se realizarán únicamente: "cuando haya posibilidades razonables de éxito, no supongan riesgo grave para la salud de la mujer o de la posible descendencia, y previa aceptación libre y consciente de su aplicación por parte de la mujer".

De tal forma que, si se incumple esta premisa, los miembros del equipo que realizó la TRA y los directores del centro estarían sujetos a "las responsabilidades que legalmente correspondan" (artículo 18.2, Ley 14/2006). 
Por otra parte, el artículo 5.1 b) de la Ley 44/2003, del 21 de noviembre, de ordenación de las profesiones sanitarias, establece que deben usarse racionalmente los recursos diagnósticos y terapéuticos, y evitar así su inadecuada utilización.

Otra corriente de pensamiento considera que una mujer que haya dado su consentimiento a someterse a una TRA a pesar de la existencia de graves riesgos, no dispondría de legitimidad para exigir responsabilidades por los perjuicios que pudieran surgir, pero sí el hijo nacido y perjudicado por la aplicación de dicha TRA (Díaz, 2007) en una acción conocida en el mundo anglosajón como wrongful life (Emaldi Cirión, 2001).

En alguna ocasión, profesionales de la reproducción asistida se han declarado objetores de conciencia a la realización de las técnicas; por ejemplo, en casos de parejas en las que alguno de sus miembros, o ambos, estaban enfermos de hepatitis B y C o afectados por el VIH (Abellán, 2008). La objeción de conciencia consiste en la renuncia a llevar a cabo una actuación que es legal en el ámbito profesional por razones religiosas o ideológicas. En España no existe una normativa que regule la objeción de conciencia médica, pero podría justificarse la apelación a esta, atendiendo al artículo 16.1 de la Constitución Española, donde se garantiza la libertad de conciencia y religiosa de las personas. En esta misma línea está el artículo 17 de la Guía de Ética Médica Europea (aprobada el 6 de enero de 1987 en la Conferencia Internacional de Órdenes Médicas), en el que además se establece que el médico objetor "invitará a los interesados a solicitar el parecer de otros colegas", así como el Código de Ética y Deontología Médica de la Organización Médica Colegial de España. No obstante, esta última institución no es mencionada en la legislación española.

En cuanto a los pacientes aquejados de enfermedades importantes como el SIDA o la hepatitis B y C, Sánchez Hernández (2007) defiende que la gravedad del riesgo de transmisión a la descendencia no debe entenderse en términos probabilísticos (es decir, atendiendo a la carga viral presente en el organismo de la madre), sino como la propia gravedad de la patología en cuestión. Siguiendo dicho criterio, en este tipo de casos solo sería aceptable llevar a cabo una TRA si la carga viral en los pacientes es prácticamente inexistente o si tecnologías como los lavados seminales garantizan la ausencia de la enfermedad en la descendencia.

\section{Diagnóstico genético preimplantatorio. Las controversias por selección de embriones no portadores de enfermedades}

El DGP permite obtener una descendencia libre de enfermedades genéticas, descartando para su transferencia al útero aquellos embriones que presenten en su ADN la anomalía responsable de la enfermedad en cuestión. Por tanto, y a diferencia de la creencia de gran parte de la sociedad, se escogen los embriones que están libres de enfermedades y no se llevan a cabo tratamientos sobre ningún embrión enfermo. Esta técnica presenta algunos puntos polémicos:

1. Requiere la obtención de un mayor número de embriones que una FIV común.

2. Los embriólogos determinan los embriones que son "normales" y los que no lo son.

3. Existe la posibilidad de descartar embriones en los que no es segura la aparición futura de una enfermedad. Son los casos de 
las afecciones de expresión tardía, las debidas a múltiples factores, las de manifestación fenotípica irregular y de predisposiciones a determinadas enfermedades.

4. El DGP puede ser un instrumento para el perfeccionamiento de las personas (eugenesia).

Estas cuestiones exigen el establecimiento de unos límites a la hora de seleccionar embriones y condicionar la constitución genética de la descendencia; es decir, debe haber una armonía entre la autonomía de los progenitores y la responsabilidad con sus hijos en cuanto a la preservación de su dignidad humana y el libre desarrollo de su personalidad (Abellán, 2007).

En nuestro país, la realización del DGP para poder detectar patologías genéticas severas, de manifestación temprana y sin cura para seleccionar los preembriones no afectos para su transferencia, o para evitar la transferencia al útero materno de preembriones con pocas probabilidades de resultar viables debido a alteraciones cromosómicas, debe ser comunicada a la autoridad sanitaria correspondiente, la cual informará a su vez a la CNRHA (artículo 12.1, Ley 14/2006).

La CNRHA debe ser informada, al menos una vez cada seis meses, de las prácticas de DGP aplicadas en estos casos (artículo 20.5, Ley 14/2006). Pueden constituirse comisiones homólogas en cada autonomía, pero entre sus atribuciones solo están las de ofrecer soporte y colaboración a la CNRHA (artículo 20.6, Ley 14/2006).

La aplicación del DGP en otros supuestos o de técnicas terapéuticas en el preembrión requiere la autorización expresa, caso a caso, de la autoridad sanitaria correspondiente, previo informe favorable de la CNRHA (artí- culos 12 y 13, Ley 14/2006); aunque en líneas generales, puede afirmarse que en España existe bastante flexibilidad para la aplicación del DGP, sin excesivos controles de la Administración.

Otra cuestión que nos podemos plantear dentro de este apartado es si está permitida la transferencia de embriones afectados o con riesgo de llegar a estarlo por enfermedades graves. Hay que indicar que no se permite, y que en estos casos la transferencia está prohibida, aunque una pareja haya dado su consentimiento (artículo 3.1, Ley 14/2006). Del mismo modo, cuando se considera necesaria la realización del DGP, pero una pareja se niega, el equipo médico no debe llevar a cabo la FIV/ICSI. En caso contrario, se podrían exigir responsabilidades legales a este equipo y a la dirección del centro, ya que por omitir información se estaría transmitiendo una enfermedad hereditaria evitable a la descendencia (artículo 18.2, Ley 14/2006), lo cual se estima como una infracción grave (art. 26.2, b), $2^{\text {a }}$, Ley 14/2006).

Además, se consideran infracciones muy graves la producción de híbridos interespecíficos que empleen material genético humano (salvo en casos permitidos), la transferencia nuclear con fines reproductivos, la selección del sexo o la manipulación genética con fines no terapéuticos o terapéuticos no autorizados (artículos 26.2, c), 7 $7^{\text {a }} 9^{\mathrm{a}}$ y $10^{\mathrm{a}}$, Ley $14 / 2006$ y artículo 159 de la Ley Orgánica 10/1995, del 23 de noviembre, del Código Penal, modificada por la Ley Orgánica 1/2015, del 30 de marzo), castigadas con multas que pueden alcanzar el millón de euros (artículo 27.1, Ley 14/2006).

Hay algunos supuestos que indican que es legal la selección del sexo de la descendencia. Vamos a verlo con más detalle. 
La selección del sexo por criterios de preferencia de los progenitores está prohibida. Desde el punto de vista ético, la selección del sexo no terapéutica puede llevar a problemas como la discriminación económica (solo la gente más adinerada podría acceder a ella) o el desequilibrio demográfico (Junquera de Estéfani, 1998). No obstante, existen sectores que la defienden basándose en el principio de libertad reproductiva de las parejas y en la opinión de que no tendría por qué desarrollarse una falta de equilibrio entre la población de ambos sexos, ya que las preferencias de cada familia son distintas.

Para salvar el obstáculo de la prohibición en España, algunas parejas deciden viajar a un país extranjero donde sí esté permitida la selección del sexo no terapéutica. $\mathrm{Si}$, por ejemplo, un centro de reproducción asistida español envía embriones congelados pertenecientes a alguna de estas parejas a dicho país (acto no prohibido en sí mismo), pero con el fin de que con estos se lleve a cabo un DGP para selección de sexo no terapéutica, estaría violando el artículo 6.4 del Código Civil: "Los actos realizados al amparo del texto de una norma que persigan un resultado prohibido por el ordenamiento jurídico, o contrario a él, se considerarán ejecutados en fraude de ley y no impedirán la debida aplicación de la norma que se hubiere tratado de eludir".

En cambio, la selección del sexo para evitar el nacimiento de hijos/as que sufran las enfermedades descritas en el artículo 12.1 de la Ley 14/2006 está totalmente justificada según la legislación española. Pero, ¿estaría justificada para evitar el nacimiento de hijos/ as portadores de una de estas enfermedades? Es decir, en este caso el DGP no se solicitaría para evitar el padecimiento de la patología en los hijos/as que de ningún modo podrían padecerla, sino en los nietos/as de la pareja que solicita la técnica. A este respecto, el artículo 8.2.c) de la ya derogada Ley 42/1988, del 28 de diciembre, de donación y utilización de embriones y fetos humanos o de sus células, tejidos u órganos, establecía que el uso de las técnicas genéticas se podría permitir con propósitos curativos, especialmente para elegir el sexo en el caso de afecciones asociadas a los cromosomas sexuales y fundamentalmente al cromosoma $\mathrm{X}$, previniendo su transferencia. Según este enunciado, que no concreta si la enfermedad debe ser padecida por los hijos/as, sino que solo trata el tema de la transmisión, el DGP estaría justificado para el caso planteado.

El artículo 12.1 de la Ley 14/2006 nos dice que el objetivo del DGP es seleccionar los preembriones no afectos para su transferencia. Así pues, ¿un embrión portador de una enfermedad es considerado como "afecto" o como "no afecto"? Si es considerado como "afecto", el DGP para evitar su transferencia no requeriría permiso de la autoridad sanitaria; mientras que si no es considerado como tal sí la requeriría, previo informe de CNRHA. En cualquier caso, el DGP en este supuesto no estaría prohibido de antemano.

Por otra parte, el artículo 14 del convenio para la protección de los derechos humanos y la dignidad del ser humano con respecto a las aplicaciones de la biología y la medicina (véase el Instrumento de Ratificación del convenio para la protección de los derechos humanos y la dignidad del ser humano con respecto a las aplicaciones de la biología y la medicina [convenio relativo a los derechos humanos y la biomedicin]), hecho en Oviedo el 4 de abril de 1997), establece que: "no se admitirá la utilización de técnicas de asistencia médica a la procreación para elegir el sexo 
de la persona que va a nacer, salvo en los casos en que sea preciso para evitar una enfermedad hereditaria grave vinculada a sexo".

A partir de esta normativa se entiende que la selección del sexo solo se justifica si se evita el sufrimiento de la enfermedad en "la persona que va a nacer", y no en descendientes de generaciones posteriores (Abellán y Sánchez-Caro, 2009).

Otro aspecto polémico es el DGP solicitado por los usuarios de una TRA (FIV/ICSI) cuando no está médicamente indicado. A este respecto, cabe señalar que el artículo 1.1 de la Ley 14/2006 indica que las TRA por realizar deben estar acreditadas científicamente y clínicamente indicadas, y que las técnicas destinadas a la prevención de enfermedades genéticas se llevarán a cabo siempre que existan las garantías diagnósticas y terapéuticas suficientes.

Los pacientes no pueden exigir que los médicos cometan actos ilegales, poco éticos o innecesarios (Jonsen et al., 2005), como resulta en algunos casos un método tan invasivo como el DGP. En esta línea podemos encontrar el artículo 5.1 a) y b) de la Ley $44 / 2003$, donde se remarca que los profesionales de la sanidad deben prestar "una atención técnica y profesional adecuada a las necesidades de salud de las personas", no a sus deseos o caprichos. Además, deben hacer "un uso racional de los recursos diagnósticos, evitando su sobreutilización".

Uno de los supuestos que requieren la autorización, caso a caso, de la autoridad sanitaria correspondiente y de un informe favorable de la CNRHA es el DGP extensivo o con fines terapéuticos a terceros. Esto quiere que en este caso la selección de embriones no solo se aplica para descartar aquéllos que presenten anomalías, sino también para escoger los embrio- nes con una compatibilidad de HLA con otra persona (habitualmente un hermano) afectada por una enfermedad. Tras el nacimiento, niño o niña actúan como donantes de células de cordón umbilical o de médula ósea para la curación de su hermano. El niño donante es coloquialmente conocido como "bebé medicamento". Además, la Organización Nacional de Trasplantes, como institución coordinadora y asesora del Ministerio de Sanidad, tiene un papel importante en la toma de decisiones en estos casos (disposición adicional $3^{\mathrm{a}}$, Ley 14/2006). El DGP extensivo es un asunto polémico, porque puede considerarse como una instrumentalización del ser humano.

Para el Comité Consultatif National d'Ethique pour les sciences de la vie et de la santé (Comité Nacional de Bioética francés [2002]), el DGP extensivo solo es aceptable cuando existe un deseo real de concebir un niño, independientemente del beneficio que su nacimiento pueda suponer para un hermano. A partir de este planteamiento, pueden surgir cuestiones que merecen una reflexión (Abellán y Sánchez-Caro, 2009):

- La posibilidad de que ninguno de los embriones obtenidos mediante FIV sea compatible con el hermano enfermo, pero sí que sean embriones sanos a los que se les debería dar un destino reproductivo (según Terribas [2006b], 3 de cada 4 embriones sanos no son compatibles con el hermano enfermo). Por tanto, un problema del DGP extensivo es el hecho de tener que descartar embriones sanos.

- La vinculación (física y psicológica) futura y forzada entre hermanos, situación en la que uno de los hermanos es "reservorio" del otro, con lo cual pueden quedar sometidos a continuas intervenciones y trasplantes, ya que no todos los casos se solucionan con 
un único trasplante al momento del nacimiento. Además, en caso de no alcanzar el éxito en la curación del hermano enfermo, el otro hermano podría padecer un sufrimiento de tipo psicológico, con lo que los males que pueden derivarse a partir del DGP extensivo pueden resultar superiores al beneficio esperado (Terribas, 2006b).

En España, la CNRHA (2004) recomendó que no se prohibiera con carácter general el DGP extensivo. Soutullo (2004) defiende la técnica por considerar que respeta los cuatro grandes principios de la bioética: no maleficiencia, beneficiencia, autonomía y justicia (Beauchamp y Childress, 1979).

\section{La donación de gametos y embriones: remuneración, anonimato, elección del donante, condiciones y pruebas exigidas para poder ser donante}

Respecto a la donación de gametos y embriones, el uso de gametos donados se contempla en alguno de estos supuestos (Matorras y Hernández, 2007):

- Pacientes afectados por infertilidad relacionada con los gametos.

- Voluntad de evitar la transmisión de enfermedades genéticas a la descendencia por imposibilidad de ser diagnosticadas en un DGP.

- Mujeres sin pareja masculina.

El artículo 5 de la Ley 35/1988, sobre técnicas de reproducción humana asistida (ya derogada) constituye la primera normativa que permite la donación de gametos y embriones en España.
En cuanto a las condiciones que se exigen para ser donante, debemos indicar que según el artículo 5 de la Ley 14/2006, vigente en la actualidad, las personas donantes han de poseer plena capacidad de obrar (teniendo en cuenta lo que dispone el Código Civil español, la tienen los mayores de edad no incapacitados legalmente). La edad máxima de las donantes de ovocitos es de 35 años, mientras que en el caso de los donantes de semen, la edad máxima es de 50 años, como se especifica en el artículo 2.1 del Real Decreto 412/1996, del 1 de marzo, por el que se establecen los protocolos obligatorios de estudio de los donantes y usuarios relacionados con las técnicas de reproducción humana asistida y se regula la creación y organización del Registro Nacional de Donantes de Gametos y Preembriones con fines de reproducción humana. Dicho registro no se ha desarrollado todavía, pese a ser una idea concebida en 1988.

Toda persona con intención de donar gametos debe presentar un adecuado estado de salud, tanto físico como psicológico, no presentar antecedentes de enfermedades transmisibles a la descendencia o a la receptora de los gametos y haber engendrado menos de seis descendientes, independientemente de que haya sucedido por reproducción asistida o natural. Se impone esta limitación para evitar los inconvenientes de posibles uniones consanguíneas futuras y para proteger a las mujeres con intención de donar frecuentemente de los riesgos de los tratamientos hormonales. Por tanto, los donantes deben comunicar antes de cada donación si han realizado otras previamente, cuándo y en qué centro (artículo 5.7, Ley 14/2006). Asimismo, el artículo 26.2, b), $11^{\text {a }}$ de la misma ley considera que "la realización continuada de prácticas de estimulación ovárica que puedan resultar lesivas para la 
salud de las mujeres donantes sanas" es una infracción grave.

Para evaluar los requisitos que debe reunir todo donante, los candidatos y candidatas deben superar un interrogatorio y un examen físico. Se les realiza obligatoriamente un test para aquellas enfermedades genéticas con una prevalencia significativa en la etnia a la que pertenecen (anexo IV del Real Decreto-ley 9/2014, de 4 de julio, por el que se establecen las normas de calidad y seguridad para la donación, la obtención, la evaluación, el procesamiento, la preservación, el almacenamiento y la distribución de células y tejidos humanos, y se aprueban las normas de coordinación y funcionamiento para su uso en humanos). Exceptuando esta exigencia, cada centro realiza las pruebas que considera oportunas. Si un candidato es descartado, se le debes informar las razones (artículo 6.3, R.D. 412/1996).

De todo ello se encarga el equipo asistencial (miembros de un centro de reproducción asistida con acreditación oficial), que elige a la persona más adecuada para cada receptora, según sus características físicas y genéticas. La elección del donante se lleva a cabo con la intención de encontrar, dentro de lo posible, la máxima compatibilidad fenotípica e inmunológica posible con la mujer receptora (artículo 6.4, Ley 14/2006). Existe un sector de los profesionales de la reproducción asistida que defiende que esta máxima compatibilidad debería buscarse respecto a la pareja de la mujer receptora, siempre que esta persona exista, es decir, siempre y cuando no se trate de un caso de mujer sola con deseos de maternidad.

La donación debe ser anónima, confidencial, por lo que la usuaria no puede seleccionar ni conocer a su donante. Según el artí 26.2, b), $5^{a}$ de la Ley 14/2006, la ruptura de las condiciones de confidencialidad se considera una infracción grave. Muchas voces críticas con esta norma defienden el derecho a conocer la identidad de los padres biológicos como algo inherente al ser humano (Nicolás, 2006) y lo hacen apoyándose en distintos artículos de la Constitución Española.

No obstante, tanto la receptora como los hijos nacidos tienen derecho a recibir información general sobre dicho donante exceptuando, evidentemente, su identidad. Según el artículo 5.5 de la Ley 14/2006, la identidad del donante puede ser excepcionalmente revelada en alguno de estos casos, de forma restringida y sin publicidad:

1. "Peligro cierto para la vida o la salud del hijo".

Por ejemplo, cuando sea indispensable un trasplante por parte del padre biológico al hijo para salvar su vida. Sin embargo, el "peligro para la salud del hijo" es un concepto subjetivo, en el que no están claramente definidos los límites. Así pues, se ha dado pie para que los hijos nacidos a partir de gametos de donante que tengan mala relación con sus padres legales aduzcan trastornos psicológicos para conocer la identidad de sus padres biológicos.

2. "Cuando proceda con arreglo a las leyes procesales penales".

Por ejemplo, en el caso de que un donante oculte una enfermedad grave e indetectable por el equipo médico del centro de reproducción.

El anonimato de los donantes permite preservar su intimidad y ofrecerles una estabilidad familiar, tanto a estos como a las familias que recurren a la reproducción asistida (García, 2004). Además, si este principio del anonimato no fuese de obligado cumplimiento, el número de donaciones disminuiría, como ha sucedido en el Reino Unido desde 
que se modificó la normativa, país desde el cual llegan a España parejas con problemas de esterilidad en busca de las soluciones que les proporciona la mayor flexibilidad de la legislación española en cuanto al asunto de la confidencialidad de los donantes.

La donación es altruista, es decir, los donantes no reciben contraprestaciones, salvo una "compensación económica resarcitoria" establecida por el artículo 5.3 de la Ley 14/2006, y justificada por las molestias físicas y los gastos de desplazamiento y laborales derivados de la donación. Los donantes son captados en campañas promulgadas por los propios centros de reproducción, los cuales no pueden ofrecer incentivos económicos para promover las donaciones. En el mismo artículo, también se establece que "el Ministerio de Sanidad y Consumo, previo informe de la Comisión Nacional de Reproducción Humana Asistida, fijará periódicamente las condiciones básicas que garanticen el respeto al carácter gratuito de la donación"; sin embargo, no se ha cumplido con esta premisa, lo que ha propiciado cierto descontrol en el asunto al que hace referencia, con el riesgo de la aparición de un mercado oculto. Lo cierto es que en los últimos años el número de donaciones de gametos no ha dejado de aumentar, aunque no puede afirmarse con rotundidad si se debe a la necesidad económica o a la creciente aceptación de la sociedad hacia las técnicas de reproducción asistida.

La legislación actual en este sentido guarda un claro vínculo con la cultura y la historia que nos preceden. Por ejemplo, el derecho romano consideraba al cuerpo humano como res extra commercium, es decir, fuera del comercio. Esta misma afirmación puede ser interpretada en el artículo 1271 del Código Civil: "Pueden ser objeto de contrato todas las cosas que no están fuera del comercio de los hombres".

La bioética europea tradicionalmente ha entendido la donación como un acto altruista y sin ánimo de lucro (Gracia, 2004), y así se pone de manifiesto en el artículo 21 del Convenio sobre derechos humanos y biomedicina, más popularmente conocido como Convenio de Oviedo, y al que ya nos hemos referido anteriormente.

Jurídicamente, el ser humano no posee la propiedad de su cuerpo, sino su titularidad, pero esto no impide que pueda decidir sobre él cuando ello implica la posibilidad de mejorar la salud de otra persona (Michaud, 2000). No obstante, la donación puede ser revocada en caso de que el donante necesite los gametos para sí mismo, y de esta manera él mismo se haría cargo de los gastos provocados al centro (artículo 5.2, Ley 14/2006).

En España, la compensación económica por la donación de ovocitos se sitúa entre los 500 y los $1000 €$. En Cataluña, las clínicas han acordado una cantidad única para evitar la competencia entre centros: $900 €$ por proceso de donación de óvulos y $50 €$ en el caso de las donaciones de esperma (Rodríguez y Ramírez de Castro, 2009).

Por otra parte, a los usuarios de las TRA que usan gametos de donantes sí se les pueden repercutir los gastos de obtención, mantenimiento o manipulación de estos, siempre que se haga sin ánimo de lucro por parte del centro de reproducción (artículo 3.5, Real Decreto-Ley 9/2014).

La donación es un contrato formalizado por escrito entre el donante y el centro autorizado, y antes de ser firmado el donante debe ser informado acerca de los objetivos y las consecuencias de esa acción (artículo 5.1, 
Ley 14/2006). No obstante, existe el derecho a realizar donaciones condicionadas (artículo 618 y ss. del Código Civil); es decir, el donante puede establecer restricciones respecto al uso que se le va a dar al material donado. Por ejemplo, puede especificar el tipo de modelo familiar al que quiere destinar sus gametos o embriones (Abellán, 2006), o donarlos solamente a parejas que hayan superado un estudio psicológico, etc.

Para determinar la filiación de los nacidos por TRA heteróloga (con contribución de donante), pueden distinguirse dos criterios: genético (representado por aquellos que aportan los gametos) y volitivo (representado por quienes acuden a los centros de reproducción con la intención de tener un hijo, con "voluntad procreacional").

Para iniciar el tratamiento de reproducción asistida, es necesario que la paciente y su cónyuge (si lo hubiese) presten su consentimiento por escrito para establecer la filiación legal de la descendencia que se obtenga, la cual no podrá ser impugnada por ninguno de los firmantes tras la ejecución de la técnica. En el supuesto de que la mencionada descendencia descubra en un futuro la identidad de sus progenitores biológicos, en ningún caso se permitiría la modificación de la filiación legal (véase Sentencia 116/1999, de 17 de junio de 1999. Recurso de inconstitucionalidad 376/1989. Promovido por Diputados del Grupo Parlamentario Popular contra la Ley 35/1988, de 22 de noviembre, de Técnicas de Reproducción Asistida, en su totalidad $\mathrm{y}$, subsidiariamente, contra distintos apartados de la misma. Voto particular), al contrario de lo que sucede con los nacidos por reproducción natural.

Así pues, como se ha visto, la legislación española otorga más valor al elemento voli- tivo -confirmado con el consentimiento por escrito- que al genético a la hora de asignar la filiación. Esta postura viene reforzada por el artículo 7.2 de la Ley 14/2006: "En ningún caso, la inscripción en el Registro Civil reflejará datos de los que se pueda inferir el carácter de la generación."

\section{El dilema sobre los fines y el destino de los embriones sobrantes de la FIV-ICSI}

En las técnicas de FIV y de ICSI suelen generarse un mayor número de embriones de los necesarios para un ciclo de una mujer, especialmente cuando se precisa un DGP en el que serán seleccionados los embriones sanos. Se realiza de este modo para obtener embriones de reserva útiles en caso de no producirse gestación en un primer intento o de voluntad de los progenitores de concebir más hijos.

El artículo 3.2 de la Ley 14/2006 informa la prohibición de transferir más de tres embriones en cada ciclo reproductivo, limitación ya contemplada en la Ley 45/2003, y que pretende evitar los riesgos asociados a los embarazos múltiples y el recurso a la reducción embrionaria. Incluso en muchos centros españoles ya se ha limitado a dos el número de embriones por transferir en los casos con mejor pronóstico (Molina et al., 2006).

Este hecho hace que surjan embriones sobrantes en procesos de FIV e ICSI, cuyo destino final se encontrará entre alguna de las siguientes opciones (artículo 11.4, Ley 14/2006):

\section{Utilización por la propia mujer o su cónyuge:}

a) Si la cesión es para el uso reproductivo "por la propia mujer", es decir, únicamente a esta y no al otro miembro de la pareja, 
solo nos podemos encontrar en dos situaciones:

- Separación o divorcio de la pareja y acuerdo entre ambos (autorización del exesposo o compañero sentimental) para la transferencia de embriones a la mujer. Conviene tener en cuenta que ninguno de los miembros de la pareja podrá impugnar la filiación matrimonial del hijo nacido (artículo 8.1, Ley 14/2006), es decir, ambos son legalmente e irrevocablemente los progenitores. Además, el varón no puede renunciar a sus obligaciones como padre, ya que iría en perjuicio del hijo e atentaría contra el artículo 6.2 del Código Civil: "La exclusión voluntaria de la ley aplicable y la renuncia a los derechos en ella reconocidos serán válidas cuando no perjudiquen a terceros".

- Fecundación post mortem.

b) Si la cesión es para uso reproductivo del cónyuge, la legislación solo ha podido referirse a un cónyuge femenino y, por tanto, a matrimonios de mujeres, ya que si se tratara de un cónyuge masculino no se estaría respetando el anonimato de las donaciones (sería una donación dirigida de la mujer progenitora a la receptora del embrión) ni la prohibición de la gestación por sustitución (artículo 10, Ley 14/2006), en caso de que el varón deseara tener un hijo a título personal.

2) Donación con fines reproductivos.

3) Donación con fines de investigación. La pareja o la mujer sola deben ofrecer un consentimiento por escrito para realizar esta donación a proyectos concretos, previa explicación del objetivo que se busca en la investigación y demás implicaciones que acarrea (artículo 16.2, Ley 14/2006). Según el artículo 32.1 del texto legislativo denominado "Ley 14/2007, del 3 de julio, de investigación biomédica", este consentimiento puede ser revocado "en cualquier momento sin que afecte a la investigación realizada". Este tipo de investigaciones debe ser autorizado por la CNRHA (artículo 15.1 d), Ley 14/2006) o por la Comisión de Garantías para la Donación y Utilización de Células y Tejidos Humanos (creada a partir de la Ley 14/2007). Además, solo se permite la investigación con embriones si no se han desarrollado in vitro más allá de 14 días tras la fecundación, sin contar el tiempo en el que han estado crioconservados (art. 15.1 b), Ley 14/2006).

4) Cese de la conservación sin otra utilización. Este es el único de los destinos que solamente puede llevarse a cabo cuando se haya agotado el plazo máximo de conservación de los embriones, que expira cuando la potencial receptora deja de reunir las condiciones clínicas adecuadas para que se le practique una TRA (artículo 11.4, Ley 14/2006). Obviamente, este precepto debe aplicarse tanto para los embriones congelados como para los que todavía no lo han sido.

La decisión acerca de este destino está íntimamente relacionada con la consideración bioética que se tenga del estatuto del embrión:

1. Concepción del embrión como realidad personal: considera al embrión in vitro como persona desde el momento de la fecundación.

2. Concepción moral gradual del embrión: en función de la etapa de desarrollo del embrión, el grado de respeto y de protección legal que merece varía. 
Esta tendencia ha influido en la distinción que se hace en el artículo 1.2 de la Ley 24/2006 entre "preembrión" o "embrión preimplantatario" y "embrión" o "embrión posimplantatario", abogando por tener presente tanto la protección de los embriones como las oportunidades terapéuticas para terceros derivadas de la investigación con estos. Asimismo, en el apartado III del Preámbulo de la Ley 14/2007 se alude a la "concepción gradualista sobre la protección de la vida humana", que se desarrolla en la legislación española.

3. Concepción naturalista del embrión. Admite la cosificación del ser humano. Dentro de esta corriente, la más extrema defiende la absoluta libertad de los progenitores para decidir el destino del embrión.

Puede afirmarse que en nuestro país el embrión ha experimentado un proceso en el cual su protección jurídica ha ido disminuyendo, ya que la Ley 35/1988 resultaba menos permisiva en este aspecto que la actual Ley 14/2006 o la Ley 14/2007 de investigación biomédica. No obstante, se mantiene la prohibición de generar embriones con objetivos distintos a la procreación (artículo 160.2 del Código Penal, artículo 33.1 de la Ley 14/2007 y artículo 18 del Convenio sobre Derechos Humanos y Biomedicina). Es por ello que todos los embriones sobrantes viables de una FIV han de ser congelados inmediatamente en los bancos autorizados para ello, con lo que se permite su destrucción o cesión para investigación en un futuro no inmediato. La congelación se puede extender hasta el momento cuando se considere que la receptora no reúne los requisitos clínicamente adecuados para la práctica de la TRA (artículo 11.3, Ley 14/2006).

Los centros de reproducción, cada dos años como mínimo, deben dirigirse a la pare- ja progenitora o mujer sola para que estos emitan un consentimiento acerca del destino que desean que se les dé a sus embriones. Si durante dos renovaciones consecutivas no es posible obtener la firma de este consentimiento, los embriones pasan a disposición de los centros, que podrán destinarlos a cualquiera de los posibles fines comentados, manteniendo la confidencialidad y anonimato de los progenitores y la gratuidad y ausencia de ánimo de lucro (artículo 11.6, Ley 14/2006).

El artículo 11.4 de la Ley 45/2003 estipulaba que, previamente al inicio de un tratamiento, era importante comprobar si la pareja o mujer sola tenían embriones criopreservados en algún centro de reproducción (aunque no se determinaba quién debía ser el responsable de esta verificación). De ser así, y si no existía ningún impedimento para disponer de ellos (patologías de los progenitores descritas en el Real Decreto 1720/2004, de 23 de julio, por el que se establecen las tipologías fisiopatológicas que permiten la superación de los límites generales establecidos para la fecundación de ovocitos en procesos de reproducción asistida), no se podía iniciar un nuevo tratamiento. Esta es una medida bastante razonable, pero su incumplimiento podría estar justificado en algunos casos: por ejemplo, mujeres con baja capacidad de respuesta ovárica que requieren un DGP, que van acumulando embriones congelados en ciclos sucesivos para su posterior análisis conjunto (Molina et al., 2006).

Sin embargo, esta situación cambió con la vigente Ley 14/2006, en la que desaparecieron los límites para generar embriones que se recogían en la norma anterior, estableciendo que esos límites se determinarían según las indicaciones médicas de cada caso (apartado II, Exposición de Motivos, Ley 14/2006). Pero también hay que tener en cuenta que la 
generación de más embriones de los necesarios para asegurar el éxito de una TRA es una infracción grave (artículo 26.2, b), 9ª Ley 14/2006).

\section{Otros dilemas relacionados con la producción asistida}

\section{La embriodonación "a futuro"}

Este tipo de donación es consecuencia directa de la donación de ovocitos. Dado que la congelación de ovocitos es muy compleja y tiene un elevado coste económico, los centros suelen plantearse la fecundación de estos ovocitos con semen de donantes, con lo cual se generarían embriones de reserva que podrían ser utilizados en el futuro con fines reproductivos.

El aspecto positivo de esta forma de proceder sería el hecho de que los embriones creados proceden de gametos de donantes que han superado controles para garantizar que presentan un buen estado de salud psicofísica (artículo 5.6, Ley 14/2006). Es decir, estos embriones son, en principio, más seguros que los embriones sobrantes de los usuarios de las TRA, que no pasan estos controles.

Sin embargo, este procedimiento no es legal por los siguientes motivos:

1. No es una técnica clínicamente indicada (artículo 1.1, Ley 14/2006).

2. Queda prohibida la generación de más embriones de los necesarios para garantizar el éxito reproductivo de una mujer o una pareja determinada (artículo 26.2, b), 9ª). En el caso de la embriodonación "a futuro" ni siquiera existe una mujer o pareja conocida en el momento de la fecundación.

3. La congelación de los ovocitos sería la técnica de menor invasividad posible de las que se presentan para alcanzar el mismo fin.

La FIV mixta

La FIV mixta es de una clase que puede tener dos modalidades:

1. Los ovocitos de una mujer son fecundados con espermatozoides de dos hombres distintos (normalmente la pareja de la mujer y un donante).

2. Los espermatozoides de un hombre son utilizados para fecundar ovocitos de dos mujeres distintas (normalmente la pareja del hombre y una donante).

Según el artículo 26.2.c. $5^{\mathrm{a}}$ y $6^{\mathrm{a}}$, la transferencia al útero, en un mismo acto, de embriones originados con espermatozoides de más de un hombre o con ovocitos de más de una mujer es una infracción muy grave. Se realiza esta prohibición para poder conocer el origen genético de las personas (Abellán y Sánchez-Caro, 2009).

Lo que no estaría prohibido, siempre y cuando esté clínicamente indicado, sería transferir en primer lugar los embriones creados con los gametos de la pareja, y en caso de no tener éxito reproductivo, transferir posteriormente los embriones creados con gametos de donante (conviene especificar que todos los embriones se han generado en el mismo instante, pero de forma separada, según se hayan usado gametos de donante o no).

La congelación de gametos para preservación de la fertilidadLa Ley 35/1988 establecía que el plazo máximo para criopreservación de semen era de cinco años (artículo 11.1). El primer informe que realizó la CNRHA (1998) contenía la propuesta de ampliar dicho plazo por los siguientes motivos: 
- La seguridad y utilidad en las TRA de muestras congeladas durante más de 10 años había quedado probada.

- No es lógico establecer un plazo de cinco años en el caso de la Criopreservación Terapéutica de Semen (CTS), realizada para hombres muy jóvenes y adolescentes que van a someterse a tratamientos esterilizantes.

De este modo, la Ley 45/2003 pasó a permitir la criopreservación del semen durante toda la vida del varón. Además, el artículo 11.3 de la actual Ley 14/2006 permite la congelación de ovocitos hasta el momento cuando la receptora deje de cumplir los requisitos para ser sometida a una TRA.

\section{La procreación post mortem}

La procreación post mortem consiste en la utilización por parte de la esposa o de la compañera de un varón fallecido, del semen de este o los embriones generados con sus espermatozoides con el fin de engendrar un hijo.

Los argumentos a favor de este tipo de procreación serían:

1. No hay preceptos constitucionales que prohíban expresamente la procreación post mortem (Pérez Monge, 2002).

2. La procreación post mortem refuerza el derecho constitucional de la mujer al libre desarrollo de su personalidad (Pérez, 2002).

3. Se cumple el deseo en vida del padre de procrear (Pérez, 2002).

4. Resultaría un contrasentido que una mujer pueda fecundarse con semen de un donante anónimo y no con el de su marido, aunque haya fallecido (De Miguel, 2004).

Como argumentos en contra se encuentran los siguientes:
1. El futuro hijo nace en una situación de orfandad originada deliberadamente (De Miguel, 2004) y se incumplen los artículos 39.3 y 39.4 de la Constitución Española (Rodríguez Guitián, 2015). De este razonamiento se deduce una postura contraria al acceso de la mujer sola a las TRA.

2. No es una técnica médicamente indicada, ya que con la muerte del varón desaparece la pareja cuya esterilidad se pretendía solucionar (Junquera de Estéfani, 1998).

3. Puede haber un interés económico subyacente en la mujer por administrar la herencia que el esposo fallecido dejaría a su hijo, con la aparición de importantes problemas jurídicos de filiación y sucesorios (Pérez, 2002).

Las posturas ante la fecundación post mortem dependen del concepto jurídico que se tenga de los gametos:

a. Los gametos como "cosas", como un bien patrimonial más. Según esta consideración, la mujer puede disponer de los espermatozoides sin el consentimiento en vida del varón y sin límites en cuanto a plazos.

b. Los gametos como un bien que no se puede poseer, sino que solo pertenece al individuo del que proceden. Según esta postura, todo uso que se le den a los espermatozoides debe haber sido autorizado por el varón que los originó (Alkorta Idiakez, 2003).

Según el artículo 9.2 de la Ley 14/2006, la procreación post mortem está permitida cuando el varón la haya aceptado en vida y la TRA se realice dentro de los 12 meses posteriores a su fallecimiento, en cuyo caso se reconocerá la paternidad de dicho varón, independientemente de si los progenitores estuviesen o no casados. Esta aceptación será válida cuando se haya ma- 
nifestado en el documento de autorización informada de las técnicas, en escritura pública, en testamento o en el escrito de instrucciones previas, y no puede ser suplida por declaraciones de familiares ni por una autorización judicial. El consentimiento puede ser revocado en cualquier momento, tanto por el varón antes de fallecer como por la mujer receptora.

En cambio, en el supuesto de realizarse una procreación post mortem ilegal (por ausencia de consentimiento del varón o por haber expirado el plazo de 12 meses), a la descendencia no le sería reconocida la paternidad del varón fallecido (artículo 9.1, Ley 14/2006). Por el contrario, Pérez (2002) defiende el reconocimiento de la paternidad en este tipo de casos por ser la opción más beneficiosa para los intereses del menor. Lledó (2007) aporta otro punto de vista: plantea que la procreación post mortem sin el consentimiento del varón o fuera del plazo de 12 meses sea legal, pero que en estos casos no se reconozca la paternidad de dicho varón, aunque esta opción incumpliría la exigencia del anonimato de los donantes de gametos (artículo 5, Ley 14/2006).

No obstante, la ley establece una excepción: se presume otorgado el consentimiento del varón cuando la mujer ya hubiera iniciado un proceso de reproducción asistida para la transferencia de preembriones constituidos antes de la muerte del mencionado varón (artículo 9.2, Ley 14/2006). El Grupo de Ética y Buena Práctica, de la SEF (2008) considera que el inicio de ese proceso es comenzar a suministrar a la mujer los fármacos preparatorios para la técnica. Rodríguez (2015) se muestra partidaria de esta medida, dado que el preembrión goza de protección constitucional.

Respecto al destino de los embriones sobrantes de una procreación post mortem, hay que indicar que transcurridos doce meses desde la muerte del varón, puede que hayan quedado embriones sobrantes. La Ley $14 / 2006$ no se manifiesta sobre el destino concreto de los embriones sobrantes de una fecundación post mortem, por lo que se aplica el criterio general sobre embriones sobrantes que fija el artículo 11.4. Como su utilización por la propia mujer ya no sería legal, esta puede escoger para los embriones entre esos tres destinos:

1. Donación a otras parejas.

2. Cesión para la investigación.

3. Destrucción (sin necesidad de esperar a que la mujer deje de cumplir con los requisitos adecuados para que se le realice la técnica).

\section{La maternidad subrogada}

Una "madre de alquiler" es una mujer que gesta y da a luz a un niño, y que ha acordado con otra persona o pareja renunciar a cualquier derecho sobre ese niño y entregárselo, generalmente a cambio de una retribución económica. La mujer que no da a luz suele recurrir a la maternidad subrogada porque no puede llevar a cabo un embarazo, es decir, existe una indicación médica, por lo que algunos sectores defienden su práctica controlada (Ruiz, Crespo y Pellicer, 2000). En otros casos, quienes desean recurrir a esta práctica son personas de elevado nivel económico y edad avanzada, para evitar las molestias de un embarazo o como alternativa a la adopción, lo cual puede degenerar en una posible comercialización del cuerpo femenino. Otros inconvenientes de la maternidad subrogada son:

- El posible deseo de la mujer gestante de quedarse con el hijo y la depresión que puede sufrir al verse obligada a entregarlo 
- Posible detección en el feto de anormalidades, solicitud de aborto terapéutico por parte de las personas que hacen el encargo y la negativa de la mujer gestante.

- Posible divorcio de la pareja estéril durante el embarazo.

- Posible chantaje por parte de la madre de alquiler hacia quien hace el encargo para obtener más dinero.

Por otra parte, existen argumentos que apoyan la maternidad por sustitución:

- La mujer gestante está en su derecho de usar su cuerpo con esta finalidad (De Miguel, 2004).

- Junquera (1998) la defiende porque entiende que así se salva la vida de aquellos que morirían en el seno de su madre por causas naturales o por abortos.

- Alkorta (2003) está a favor siempre de que se haga de forma altruista para que una mujer que no puede seguir un embarazo pueda ser madre, siendo las mujeres participantes hermanas o amigas.

Se pueden diferenciar varios tipos de maternidad subrogada según el origen de los gametos (De Miguel, 2004):

1. Los gametos son de la pareja que hace el encargo (subrogación parcial).

2. El semen o los óvulos son de donantes distintos a la pareja y a la madre subrogada.

3. Ambos gametos son de donantes.

4. El semen es del varón de la pareja y el óvulo de la madre subrogada.

5. El semen es de donante y el óvulo de la madre subrogada.
También pueden distinguirse distintas modalidades según la persona o personas que realicen el encargo:

a. Pareja heterosexual.

b. Pareja homosexual.

c. Mujer sola.

d. Hombre solo.

Nuestra normativa viene culturalmente influenciada por la expresión latina "mater semper certa est", es decir, la madre es aquella que sufre el parto. Así pues, según el artículo 10 de la Ley 14/2006, "será nulo de pleno derecho el contrato por el que se convenga la gestación, con o sin precio, a cargo de una mujer que renuncia a la filiación materna a favor del contratante o de un tercero" y se añade que la madre será siempre aquella que dé a luz. Por tanto, nuestra ley de reproducción no prohíbe la gestación subrogada, sino que no la reconoce.

Como consecuencia de esta norma, los varones solos y los matrimonios homosexuales masculinos no pueden acceder a la reproducción asistida.

Los centros de reproducción que accedieran a realizar una gestación subrogada, o simplemente colaborasen para que esta se llevara a cabo fuera de nuestro país, estarían cometiendo una infracción grave, por vulnerar sus obligaciones legales en el tratamiento a los usuarios de las TRA (artículo 26.2, b), 1, Ley 14/2006).

Por último, nos podemos preguntar: ¿qué ocurre cuando los españoles recurren a la gestación subrogada en otros países?

La inscripción en España de los nacidos mediante gestación subrogada fuera de nuestro país está permitida. Para ello, la Instrucción del 
5 de octubre 2010, de la Dirección General de los Registros y del Notariado, sobre régimen registral de la filiación de los nacidos mediante gestación por sustitución (BOE núm. 243, de 7 de octubre de 2010) (Guzmán, 2010 y Calvo Caravaca y Carrascosa González, 2011) estableció una serie de pautas:

1. Necesidad para la inscripción del menor de que nazca en el extranjero mediante el contrato de gestación por sustitución de una resolución judicial en la que se determine la filiación.

2. Exequátur (reconocimiento) para la resolución judicial extranjera.

3. Si la resolución judicial extranjera tiene su origen en un procedimiento análogo a uno español de jurisdicción voluntaria, se establece un control por parte del encargado del Registro civil, previamente a la inscripción, si dicha resolución judicial extranjera se puede reconocer en España.

4. La inadmisión de la certificación registral extranjera o simple declaración, junto con el certificado médico acreditativo del nacimiento sin constar la identidad de la gestante, como título que habilite la inscripción del nacimiento y filiación.

\section{Propuestas de lege ferenda para una regulación más precisa de las Técnicas de Reproducción Asistida}

A raíz de un profundo análisis de la Ley 14/2006, diversos autores han identificado ciertos puntos que, en su opinión, merecen ser objeto de revisión. En este apartado se exponen algunas de estas sugerencias.

\section{Acceso a las TRA}

El derecho a acceder a las TRA es independiente de la orientación sexual y del estado civil de las personas. En el artículo 6.3 de la Ley 14/2006 se especifica que si la mujer estuviera casada necesita "del consentimiento del marido" para acceder a las técnicas. Por tanto, esta expresión no parece muy acertada ya que no tiene en cuenta los matrimonios formados por mujeres (Terribas, 2006a).

No resulta demasiado ético que no sea obligatorio disponer del consentimiento del varón de una pareja de hecho formalizada en un registro, para que su pareja se pueda someter a una TRA (Abellán y Sánchez-Caro, 2009)

\section{Donaciones}

La puesta en funcionamiento del Registro Nacional de Donantes de Gametos y Preembriones es la gran asignatura pendiente de la reproducción asistida española. En la Ley 35/1988 ya se hacía referencia a este registro, sin el cual es imposible, por ejemplo, comprobar si un candidato a donante ha tenido ya seis descendientes (límite marcado por la Ley 14/2006 para poder ser donante) o si una pareja que desea someterse a una FIV ya dispone de embriones en otro centro de reproducción.

\section{Generación y destino de los embriones sobrantes}

Según el Código Penal, los embriones solo pueden ser originados con la finalidad de la procreación. Para garantizar el cumplimiento de esta normativa, la ley de reproducción asistida debería establecer el número máximo de óvulos por fecundar en los procesos de FIV-ICSI, y evitar así la creación de un núme- 
ro excesivo de embriones que nunca llegarán a ser implantados.

La Ley 14/2006 permite la investigación con embriones viables congelados, lo cual podría tratarse de una violación del artículo 15 de la Constitución Española

La legislación española prioriza las alternativas reproductivas y de investigación para los embriones ante la posibilidad de destruirlos, dado que este último destino solo puede materializarse en el caso de que la mujer ya no sea clínicamente apta para someterse a una TRA, mientras que el resto de destinos pueden decidirse libremente sin ningún tipo de restricción. Este plazo puede resultar un tanto absurdo en casos en los que la pareja o la mujer sola tienen muy claro que no desean usar ellos mismos los embriones ni donarlos para ninguna causa, ya que estos embriones están destinados a permanecer criopreservados durante algunos años sin ningún sentido (Terribas, 2006a).

Aunque no está prohibido que una pareja pueda comenzar un ciclo de FIV, pese a disponer de embriones congelados con anterioridad, los centros de reproducción están legitimados para negarse a ello si no es necesario para asegurar el éxito reproductivo. Es más, el centro incurriría en una infracción grave si generara embriones de manera innecesaria (artículo 26.2, b), 9a , Ley 14/2006).

A diferencia de lo que ocurría con la Ley 45/2003, la actual Ley 14/2006 determina que los destinos de los embriones serán los mismos con independencia de su fecha de congelación. De este modo, las parejas con embriones no aptos para su donación con fin reproductivo pueden destinarlos a cualquier otro propósito.

\section{Procreación post mortem}

En el caso de la procreación post mortem, sería conveniente establecer un plazo mínimo tras el fallecimiento del varón para poder llevarla a cabo, y así evitar la toma de decisiones poco reflexionadas y fruto de la conmoción (Chen, 1986; Pérez, 2002).

\section{Maternidad subrogada}

Sería deseable una regulación uniforme a nivel internacional (Velarde, 2012) respecto a la inscripción registral de los nacidos mediante contrato de sustitución.

\section{Restricción de los ciclos de reproducción asis- tida en la sanidad pública}

La reproducción asistida es una de las prestaciones que ofrece el Sistema Nacional de Salud, como establece el Real Decreto 1030/2006, del 15 de septiembre, por el que se establece la cartera de servicios comunes del Sistema Nacional de Salud y el procedimiento para su actualización. Por tanto, son servicios que se realizan no solamente en centros privados, sino también en centros públicos. Sin embargo, ni en el mencionado Real Decreto ni en la Ley 14/2006 se estipula un límite de ciclos de reproducción asistida a los que puede someterse una paciente. El establecimiento de este tope en nuestra legislación se torna necesario para evitar malentendidos y discrepancias.

\section{Conclusiones}

Las tres leyes sobre reproducción asistida que se han promulgado en España desde 1988 son muestra de una cierta inestabilidad legislativa. Se evidencia una clara influencia de los cambios políticos en los Gobiernos sobre los cambios efectuados en la ley de reproducción, ya que cada modificación de esta ley ha sido pro- 
movida por un partido político distinto al que promovió el texto anterior.

Lógicamente, las leyes nunca podrán incluir una previsión de los avances científicos futuros y, por tanto, tampoco podrán someterlos a una regulación justa hasta que no se dispongan de amplios conocimientos sobre estos. La actual Ley 14/2006 enumera la relación de técnicas que hoy en día se aplican, aunque deja la puerta abierta a la experimentación con nuevas técnicas, previo permiso de la autoridad sanitaria. Así pues, esta parece una decisión acertada, ya que no cierra la puerta a que se produzcan nuevos avances en reproducción asistida, pero exige un control por parte de expertos en la materia.

Por otro lado, España goza, en general, de una normativa muy permisiva y avanzada en cuestiones sociales y de libertades, ya que permite el acceso de las mujeres a las TRA, independientemente de su estado civil y de su orientación sexual. Los hombres solos y las parejas homosexuales masculinas no gozan de dicho acceso, ya que la gestación subrogada no está permitida. La posibilidad de llevar a cabo fecundaciones post mortem es otro ejemplo que pone de manifiesto la gran permisividad de la ley española.

En cuanto al acceso a las TRA por parte de mujeres o parejas que padecen enfermedades, el principio de no maleficencia debe estar por encima del principio de autonomía de los pacientes. De este modo, se tiene que denegar la realización de los tratamientos cuando se ponga en peligro la salud de la mujer y de la descendencia, especialmente cuando esté en riesgo la salud de los futuros hijos, ya que obviamente estos no tienen poder de decisión (en cambio, la madre sí puede tomar decisiones autónomas, aunque puedan resultar equivocadas). Incluso sería aconsejable, al igual que ocurre con la autorización para algunos supuestos de DGP, que fuera la CNRHA la encargada de autorizar el acceso de parejas con ciertas enfermedades a las TRA en los casos en los que el centro de reproducción presente dudas acerca de la decisión por tomar.

Además, la ley prohíbe la selección del sexo, a no ser que se realice con la intención de evitar enfermedades. En este artículo se comparte esta postura y se piensa que las técnicas reproductivas no deben convertirse en un servicio "a la carta", sino que deben ser practicadas solo cuando exista una indicación médica justificada. En otras palabras, siempre se ha de intentar que el proceso reproductivo sea lo más natural posible y solamente deben hacerse excepciones cuando aparezca una indicación clínica, como ya se ha comentado.

La ley vigente ya contempla el DGP con fines terapéuticos para terceros, lo cual resulta una medida muy correcta. Diversos autores se sitúan a favor de esta técnica, siempre y cuando el niño nacido para curar a un hermano sea asimismo un niño querido y deseado por sus padres. Obviamente, en la inmensa mayoría de los casos se cumple esta condición.

Por lo referente a las donaciones de gametos, la usuaria o los usuarios de una TRA deberían tener derecho a escoger su donante, siempre y cuando este llegue al centro de reproducción a través de los usuarios y, evidentemente, esté de acuerdo con ellos en la realización de la técnica. Al igual que en el supuesto de las donaciones anónimas, estos donantes elegidos no tendrían ninguna obligación respecto de la descendencia, no recibirían ninguna remuneración y deberían superar las pruebas exigidas para poder ser donante. En caso de que los usuarios no 
deseasen seguir este procedimiento, podrían recurrir a las donaciones anónimas.

La dignidad de los embriones sobrantes de las TRA debe ser protegida, y debe primar la opción reproductiva para los embriones sanos. En el caso de los embriones que presenten anomalías, el médico responsable o la autoridad sanitaria competente son los que deciden sobre la conveniencia de darles un fin reproductivo, basándose en lo que dice el artículo 3.1 de la Ley 14/2006: "las TRA se realizarán únicamente cuando haya posibilidades razonables de éxito y no supongan riesgo grave para la salud de la mujer o de la posible descendencia". Cuando la reproducción no sea posible, debería fomentarse la opción de donar para investigación frente a la elección de destruirlos.

\section{Agradecimientos}

Proyecto I+D Excelencia MINECO DER201565810-P (2016-2018) y Proyecto Programa Prometeo para Grupos de Investigación de Excelencia de la Conselleria de Educación, Cultura y Deporte, GVPROMETEOII2015-014.

\section{Referencias}

Abellán, F. (2006). La ética en nuestro trabajo: reflexiones bioéticas en relación al diagnóstico genético preimplantatorio. Revista Asebir, 11(2), 7-9. Recuperado de http://revista. asebir.com/la-etica-en-nuestro-trabajo-reflexiones-bioeticas-en-relacion-al-diagnostico-genetico-preimplantatorio/

Abellán, F. (2007). Selección genética de embriones: entre la libertad reproductiva y la eugenesia. Granada: Fundación Salud 2000, Comares.

Abellán, F. (2008). Libertad de conciencia e inicio de la vida. Problemática en la reproduc- ción humana asistida. En Libertad de conciencia y salud. Guía de casos prácticos. (pp. 1-40). Granada: Comares.

Abellán, F. y Sánchez-Caro, J. (2009). Bioética y ley en reproducción humana asistida. Manual de casos clínicos. Granada: Comares.

Alkorta Idiakez, I. (2003). Regulación jurídica de la medicina reproductiva. Derecho español y comparado. Pamplona: Thomson-Aranzadi.

Beauchamp, T. L. y Childress, J. F. (1979). Principles of Biomedical Ethics. Nueva York: Oxford University Press.

Calvo Caravaca, A. L. y Carrascosa González, J. (2011). Notas críticas en torno a la instrucción de la Dirección General de los Registros y del Notariado de 5 de octubre 2010 sobre régimen registral de la filiación de los nacidos mediante gestación por sustitución. Cuadernos de Derecho Transnacional, 3(1), 247-262. Recuperado de https://e-revistas.uc3m.es/index.php/CDT/article/ view/1077/395

Comité Consultatif National d'Ethique pour les Sciences de la vie et de la Ssanté (CCNE) (2002). Reflexions sur l'extension du diagnostic pré-implantatoire. Avis, 72, 1-18.

Chen, C. (1986). Pregnancy after human oocyte cryopreservation. Lancet, 1, 884-886.

De Miguel Beriain, I. (2004). El embrión y la biotecnología. Un análisis ético-jurídico. Granada: Comares.

Díaz Martínez, A. (2007). Comentario jurídico al artículo 3, de la ley de reproducción. En Ó. Monje Balmaseda (Coord.), Comentarios Científico-jurídicos a la Ley sobre técnicas de reproducción humana asistida (Ley 14/2006, de 26 de mayo). (pp. 58-67). Madrid: Dykinson. 
Emaldi Cirión, A. (2001). El consejo genético y sus implicaciones jurídicas. Cátedra Interuniversitaria. Fundación BBVA-Diputación Foral de Vizcaya de Derecho y Genoma Humano. Bilbao-Granada: Comares.

España, Constitución Española (29 de diciembre de 1978). Boletín Oficial del Estado, Madrid, núm. 311.

España, Jefatura de Estado (24 de noviembre de 1988). "Ley 35/1988, de 22 de noviembre, sobre Técnicas de Reproducción Asistida". Boletín Oficial del Estado, Madrid, núm. 282.

España, Jefatura de Estado (24 de noviembre de 1995). "Ley Orgánica 10/1995, de 23 de noviembre, del Código Penal”. Boletín Oficial del Estado, Madrid, núm. 281.

España, Jefatura de Estado (22 de noviembre de 2003). "Ley 44/2003, de 21 de noviembre, de ordenación de las profesiones sanitarias". Boletín Oficial del Estado, Madrid, núm. 280.

España, Jefatura de Estado (22 de noviembre de 2003). "Ley 45/2003, de 21 de noviembre, por la que se modifica la Ley 35/1988, de 22 de noviembre, sobre Técnicas de Reproducción Asistida". Boletín Oficial del Estado, Madrid, núm. 280.

España, Jefatura de Estado (3 de diciembre de 2003). "Ley 51/2003, de 2 de diciembre, de igualdad de oportunidades, no discriminación y accesibilidad universal de las personas con discapacidad". Boletín Oficial del Estado, Madrid, núm. 289.

España, Jefatura de Estado (2 de julio de 2005). "Ley 13/2005, de 1 de julio, por la que se modifica el Código civil en materia de derecho a contraer matrimonio". Boletín Oficial del Estado, Madrid, núm. 157.

España, Jefatura de Estado (27 de mayo de 2006). "Ley 14/2006, de 26 de mayo, sobre Técnicas de Reproducción Humana Asistida". Boletín Oficial del Estado, Madrid, núm. 126.

España, Jefatura de Estado (16 de marzo de 2007). "Ley 3/2007, de 15 de marzo, reguladora de la rectificación registral de la mención relativa al sexo de las personas". Boletín Oficial del Estado, Madrid, núm. 65.

España, Jefatura de Estado (4 de julio de 2007). "Ley 14/2007, de 3 de julio, de Investigación biomédica”. Boletín Oficial del Estado, Madrid, núm. 159.

España, Jefatura de Estado (5 de julio de 2014). "Real Decreto-ley $9 / 2014$, de 4 de julio, por el que se establecen las normas de calidad y seguridad para la donación, la obtención, la evaluación, el procesamiento, la preservación, el almacenamiento y la distribución de células y tejidos humanos y se aprueban las normas de coordinación y funcionamiento para su uso en humanos". Boletín Oficial del Estado, Madrid, núm. 163.

España, Jefatura de Estado (31 de marzo de 2015). "Ley Orgánica 1/2015, de 30 de marzo, por la que se modifica la Ley Orgánica 10/1995, de 23 de noviembre, del Código Penal". Boletín Oficial del Estado, Madrid, núm. 77.

España, Ministerio de Gracia y Justicia (25 de julio de 1889). Real Decreto de 24 de julio de 1889, por el que se publica el Código civil. Boletín Oficial del Estado, Madrid, núm. 206. 
España, Ministerio de Sanidad y Consumo (27 de julio de 2004). "Real Decreto $1720 / 2004$, de 23 de julio, por el que se establecen las tipologías fisiopatológicas que permiten la superación de los límites generales establecidos para la fecundación de ovocitos en procesos de reproducción asistida". Boletín Oficial del Estado, Madrid, núm. 180.

España, Ministerio de Sanidad y Consumo (16 de septiembre de 2006). "Real Decreto $1030 / 2006$, de 15 de septiembre, por el que se establece la cartera de servicios comunes del Sistema Nacional de Salud y el procedimiento para su actualización". Boletín Oficial del Estado, Madrid, núm. 222.

España, Ministerio de Sanidad, Servicios Sociales e Igualdad (3 de diciembre de 2013). "Real Decreto Legislativo 1/2013, de 29 de noviembre, por el que se aprueba el Texto Refundido de la Ley General de derechos de las personas con discapacidad y de su inclusión social". Boletín Oficial del Estado, Madrid, núm. 289.

Farnós Amorós, E. (2011). Acceso a la reproducción asistida por parejas del mismo sexo en España: estado de la cuestión, propuestas y retos. Derecho de Familia: Revista Interdisciplinaria de Doctrina y Jurisprudencia, 49, 153-181.

García Ruiz, Y. (2004). Reproducción asistida. Derecho, conciencia y libertad. Granada: Comares.

Gracia, D. (1991). Procedimientos de decisión en ética clínica. Madrid: Triacastela.

Gracia, D. (2004). Como arqueros al blanco. Estudios de bioética. Madrid: Triacastela.
Guzmán Zapater, M. (2010). Gestación por sustitución y nacimiento en el extranjero: hacia un modelo de regulación (sobre la institución DGRN de 5 de octubre de 2010). Anuario Español de Derecho Internacional privado, 10, 731-743.

Jonsen, A., Siegler, M. y J. Winslade, W. (2005). Ética clínica. Aproximación práctica a la toma de decisiones en la medicina clínica. Madrid: Ariel.

Junquera de Estéfani, R. (1998). Reproducción asistida, filosofía ética y filosofía jurídica. Madrid: Tecnos.

Lledó Yagüe, F. (2007). Comentario jurídico art. 9. En Ó. Monje Balmaseda (Coord.), Comentarios científico-jurídicos a la Ley sobre Técnicas de reproducción humana asistida (Ley 14/2006, de 26 de mayo) (pp. 123-155). Madrid: Dykinson.

Martín Sánchez, I. (2005). El comienzo de la vida. En Bioética, Religión y Salud (pp. 135138). Madrid: Consejería de Sanidad y Consumo.

Matorras, R. y Hernández, J. (2007). Estudio y tratamiento de la pareja estéril: recomendaciones de la Sociedad Española de Fertilidad, con la colaboración de la Asociación Española para el Estudio de la Biología de la Reproducción, de la Asociación Española de Andrología y de la Sociedad Española de Contracepción. Madrid: Adalia.

Michaud, J. (2000). Aspectos éticos de los trasplantes de donantes vivos. En M. Palacios (Coord.), Bioética 2000. (pp. 325-328). Oviedo: Sibi. Ediciones Nobel..

Molina, I., Duque, C.C. y Alfonso, J. (2006). Controversias legales en reproducción asistida humana. Revista Iberoamerica- 
na de Fertilidad, 23(1), 63-70. Recuperado de http://www.revistafertilidad.org/ RecursosWEB/fertilidad/Fert-En-Febr06-Trabajo6.pdf

Morales Moreno, A.M. y Miquel González, J.M. (2007). Derecho, sociedad y familia: Cambio y continuidad. Madrid: Universidad Autónoma de Madrid, Boletín Oficial del Estado.

Nicolás Jiménez, P. (2006). La protección jurídica de los datos genéticos de carácter personal. Cátedra Interuniversitaria Fundación BBVA-Diputación Foral de Vizcaya de Derecho y Genoma Humano. Bilbao-Granada, Comares.

Organización Médica Colegial de España. (1999). Código de Ética y Deontología Médica. SEF, 12(2), 6-15.

Pérez Milán, F. (2003). La SEF ante la reforma de la Ley de Reproducción Asistida, 12 (2), 6-15.

Pérez Milán, F. (2009). Breve explicación de las técnicas reproductivas: ¿cuáles son, en qué consisten, cuándo están indicadas y qué riesgos tienen? En F. Abellán y J. Sánchez-Caro (Eds.). Bioética y ley en reproducción humana asistida. Manual de casos clínicos. Granada: Comares.

Pérez Monge, M. (2002). La filiación derivada de las técnicas de reproducción asistida. Madrid: Centro de Estudios Registrales.

Rodríguez, P. y Ramírez de Castro, N. (2009). Generosidad interesada. Diario $A B C$. Recuperado de http://www. abc.es/20090104/nacional-sociedad/ generosidad-interesada-compra-pelo-20090104.html
Rodríguez Guitián, A.M. (2015). La reproducción artificial post mortem en España: estudio ante un nuevo dilema jurídico. Revista Boliviana de Derecho, 20, 292-323. Recuperado de http://www.revistabolivianadederecho.org/index.php/ rbd/revista-digital-pdf/send/2-nuestras-publicaciones-revista-rbd/631-revista-rbd-n-20

Ruiz, A., Crespo, J. y Pellicer, A. (2000). El futuro de la reproducción asistida. Cuadernos de Medicina Reproductiva. Reproducción Asistida del siglo XXI, 6(2), 79.

Sánchez Hernández, A. (2007). Art. 3. Condiciones personales de la aplicación de las técnicas. En J. A. Cobacho Gómez (Dir.) y J. J. Iniesta Delgado (Coord.), Comentarios a la Ley 14/2006, de 26 de mayo, sobre técnicas de reproducción humana asistida (pp. 46-47). Cizur Menor: Thomson-Aranzadi.

Serna Meroño, E. (2007). Art. 6. Usuarias de las técnicas. En J. A. Cobacho Gómez (Dir.) y J. J. Iniesta Delgado (Coord.), Comentarios a la Ley 14/2006, de 26 de mayo, sobre técnicas de reproducción humana asistida (pp. 179-210). Cizur Menor: Thomson-Aranzadi.

Sociedad Española de Fertilidad (SEF) (2008). Grupo de Interés en Ética y Buena Práctica Clínica de la SEF (2008). Recuperado de http://www.sefertilidad.net/index. php?seccion=grupos\&subSeccion=etica

Sociedad Española de Fertilidad. (2011). Libro blanco sociosanitario. La infertilidad en España: situación actual y perspectivas. Madrid: Merck Serono.

Sociedad Española de Fertilidad. (2012). Registro de la Sociedad Española de Ferti- 
lidad: Técnicas de reproducción asistida (IA y FIV/ICSI). Recuperado de https:// www.registrosef.com/public/docs/ sef2012_IAFIV.pdf

Soutullo, D. (2004). Selección de embriones y principios de la bioética. Revista Derecho y Genoma Humano, 21, 185-198.

Terribas Sala, N. (2006a). Nueva ley de reproducción asistida. Revista Bioètica \& Debat, 45, 1-5.
Terribas Sala, N. (2006b). Concebir un hijo para curar al hermano enfermo. Revista Bioètica \& Debat, 45, 6-7.

Velarde D’Amil, Y. (2012). Comentario a la Sentencia de la Audiencia Provincial de Valencia núm. 949/2011 826 2311-2011: No inscripción en el Registro civil de los menores nacidos mediante gestación por sustitución. Revista sobre la Infancia y la Adolescencia, 3, 61-70. doi: https://doi.org/10.4995/ reinad.2012.1298 